\title{
NEUTRAL CARBON IN POST-ASYMPTOTIC GIANT BRANCH STARS AND PLANETARY NEBULAE
}

\author{
TATSUhiKo I. Hasegawa AND Sun KwOK ${ }^{1}$ \\ Department of Physics and Astronomy, University of Calgary, Calgary, AB T2N 1N4, Canada; hasegawa@iras.ucalgary.ca, kwok@iras.ucalgary.ca \\ Received 2002 September 18; accepted 2002 November 5
}

\begin{abstract}
The $492 \mathrm{GHz}\left({ }^{3} P_{1} \rightarrow{ }^{3} P_{0}\right)$ fine-structure line of neutral atomic carbon (C I) has been observed in the planetary nebulae (PNe) NGC 6302, IRAS 21282+5050, and NGC 7027, and in the protoplanetary nebula (PPN) AFGL 2688. The estimated C I/CO abundance ratio is higher for a more evolved object, consistent with a trend that the $\mathrm{C} \mathrm{I} / \mathrm{CO}$ ratio increases with the evolution of a post-asymptotic giant branch system from a PPN to a PN. Nondetections are also reported on 11 PPNe and extreme carbon stars. The upper limits placed on these objects suggest that they have $\mathrm{C}$ I abundances lower than the level found in the PPN AFGL 2688, again consistent with an increasing $\mathrm{C}_{\mathrm{I}} / \mathrm{CO}$ ratio with evolution.

Subject headings: circumstellar matter — planetary nebulae: individual (NGC 6302, IRAS 21282+5050) — stars: AGB and post-AGB
\end{abstract}

\section{INTRODUCTION}

The element carbon is synthesized by triple- $\alpha$ reactions during the thermal-pulsing phase of the asymptotic giant branch (AGB). The $\mathrm{C}$ nuclei are dredged up to the surface and react with oxygen to form $\mathrm{CO}$ in the photosphere. Once the $\mathrm{C}$ abundance exceeds that of $\mathrm{O}$, other carbon-based molecules $\left(\mathrm{C}_{2}, \mathrm{C}_{3}, \mathrm{CN}\right.$, etc.) form in large numbers. In the later stages of the AGB, radiation pressure on dust causes mass loss from the surface, and various other molecules can form in the stellar winds. More than 60 gas-phase molecules, the majority of them carbon-based, have been observed in the stellar winds of carbon stars (Olofsson 1996).

As these winds deplete the $\mathrm{H}$ envelope, the star will leave the AGB and evolve to higher temperatures, entering the post-AGB or the protoplanetary nebula (PPN) phase of evolution. Acetylene $\left(\mathrm{C}_{2} \mathrm{H}_{2}\right)$, commonly observed in $\mathrm{AGB}$ winds, evolve to polyacetylenic chains such as $\mathrm{C}_{4} \mathrm{H}_{2}$ and $\mathrm{C}_{6} \mathrm{H}_{2}$ and the subsequent formation of benzene $\left(\mathrm{C}_{6} \mathrm{H}_{6}\right)$ in the PPN phase (Cernicharo et al. 2001). Emission features due to aromatic and aliphatic compounds also begin to appear (Kwok, Volk, \& Hrivnak 1999; Hrivnak, Volk, \& Kwok 2000; Kwok, Volk, \& Bernath 2001) in the post-AGB phase.

The short (few thousand years) AGB-PPN-PN transition period therefore represents a fascinating laboratory to study carbon chemistry under evolving density and radiation conditions. Elemental carbon can be in ionized, atomic, molecular, and solid forms. While the molecular and solid-state forms of $\mathrm{C}$ can be traced by millimeter and infrared observations and the ionic lines of $\mathrm{C}$ can be observed in the visible and the ultraviolet, the neutral form of atomic carbon has remained difficult to trace. Theoretical studies of the chemistry during the AGB and PPN phases predict that gasphase neutral atomic carbon $\left(\mathrm{C}_{\mathrm{I}}\right)$ is a minority form of the elemental carbon (Cherchneff \& Barker 1992; Cherchneff, Glassgold, \& Mamon 1993; Millar \& Herbst 1994). On the other hand, models of photochemistry predict that $\mathrm{C}$ I is produced in significant quantities once the central star becomes hot enough to photoionize and photodissociate the (thus far molecular) circumstellar material. However, compared with molecular and dust observations, observational

\footnotetext{
${ }^{1}$ Canada Council Killam Fellow.
}

tests of the model predictions on $\mathrm{C}_{\mathrm{I}}$ in the AGB and postAGB objects have been slow in coming.

$\mathrm{C}_{\mathrm{I}}$ in a neutral, low-temperature region has only two transitions accessible with a ground-based telescope; the fine-structure lines ${ }^{3} P_{1}-{ }^{3} P_{0}$ [C I (1-0)] at $492.1607 \mathrm{GHz}$ $(609.1 \mu \mathrm{m})$ and ${ }^{3} P_{2}-{ }^{3} P_{1}\left[\mathrm{C}_{\mathrm{I}}(2-1)\right]$ at $809.3435 \mathrm{GHz}(370.4$ $\mu \mathrm{m})$. In the past 10 years, with the improving performances of receivers and telescopes in the submillimeter band, attempts have been made to observe the atomic form of carbon in AGB stars and PNe through these lines [mostly in C I $(1-0)]$. Successful detections of C I (1-0) in stellar sources and PNe have been made by Keene et al. (1993, IRC +10216), Huggins et al. (1994, $\alpha$ Ori), Bachiller et al. (1994, NGC 6720), Young et al. (1997, NGC 7293), Young (1997, AFGL 618, AFGL 2688), van der Veen, Huggins, \& Matthews (1998, IRC +10216 , $\alpha$ Ori), and Knapp et al. (2000, HD44179, IRAS 07134+1005 [=HD 56126], V Hya). A number of nondetections are also reported in the last two papers.

We have searched for $\mathrm{C}_{\mathrm{I}}(1-0)$ emission in 15 extreme carbon stars, PPNe, and PNe. The extreme carbon stars are selected from IRAS carbon stars that possess thick circumstellar envelopes and are about to evolve off the AGB (Volk, Kwok, \& Langill 1992; Volk, Xiong, \& Kwok 2000). The PPNe observed include the well-known PPN AFGL 2688, as well as candidates that were discovered as the result of survey of cool IRAS sources (Kwok, Volk, \& Hrivnak 1989; Kwok 1993; Kwok, Hrivnak, \& Geballe 1995; Kwok et al. 1996). The three PNe observed are all young (in dynamical age) with large infrared excesses. The survey sample therefore covers the several thousand year transition between the AGB and PN phases. By doing this C I survey, we hope to set stronger constraints on the fate of elemental carbon during the last stage of stellar evolution and to test predictions from chemical models. New detections of $\mathrm{C}_{\mathrm{I}}$ have been made in two PNe during the course of our search.

\section{OBSERVATIONS}

The C I ( $\left.{ }^{3} P_{1} \rightarrow{ }^{3} P_{0}, 492.1607 \mathrm{GHz}\right)$ observations were made with the James Clark Maxwell Telescope (JCMT) on several nights spread over a period between 1999 July and 2001 October. The telescope had a beam size 
TABLE 1

SUMMARY OF C I OBSERVATIONS

\begin{tabular}{|c|c|c|c|c|c|c|c|c|}
\hline Source & $\alpha(1950)$ & $\delta(1950)$ & $\begin{array}{c}\int T_{\mathrm{MB}} d V \\
\left(\mathrm{~K} \mathrm{~km} \mathrm{~s}^{-1}\right)\end{array}$ & $\begin{array}{l}T_{\mathrm{MB}} \\
(\mathrm{K})\end{array}$ & $\begin{array}{c}V_{\mathrm{LSR}} \\
\left(\mathrm{km} \mathrm{s}^{-1}\right)\end{array}$ & $\begin{array}{r}\sigma_{\mathrm{MB}} \\
(\mathrm{K})\end{array}$ & $\begin{array}{c}\Delta \nu \\
(\mathrm{MHz})\end{array}$ & Notes \\
\hline NGC $6302 .$. & 171021.30 & -370243.0 & $3.25 \pm 0.67$ & 0.250 & -40 & 0.069 & 5.00 & $2001 \mathrm{Jul}$ \\
\hline IRAS $21282+5050 \ldots \ldots$ & 212815.08 & +505048.0 & $5.10 \pm 0.51$ & 0.289 & +19 & 0.060 & 5.00 & 1999 Sep \\
\hline AFGL $2688 \ldots \ldots \ldots \ldots \ldots . . .$. & 210019.88 & +362945.0 & $\begin{array}{l}3.70 \pm 0.72 \\
7.25 \pm 0.91\end{array}$ & $\begin{array}{l}0.207 \\
0.346\end{array}$ & $\begin{array}{l}-35 \\
-35\end{array}$ & $\begin{array}{l}0.068 \\
0.104\end{array}$ & $\begin{array}{l}5.00 \\
3.97\end{array}$ & $\begin{array}{l}1999 \text { Sep } \\
1993 \text { Jun }\end{array}$ \\
\hline NGC $7027 \ldots \ldots \ldots \ldots \ldots$ & 210509.38 & +420203.0 & $\begin{array}{l}19.90 \pm 1.29 \\
21.56 \pm 1.06\end{array}$ & $\begin{array}{l}0.839 \\
0.660\end{array}$ & $\begin{array}{l}+25 \\
+25\end{array}$ & $\begin{array}{l}0.103 \\
0.088\end{array}$ & $\begin{array}{l}5.00 \\
4.96\end{array}$ & $\begin{array}{l}2001 \text { Oct } \\
1993 \text { Jun }\end{array}$ \\
\hline IRAS $02229+6208 \ldots \ldots$ & 022253.05 & +620753.61 & $\ldots \pm 0.43$ & $\ldots$ & +24 & 0.063 & 2.50 & 2001 Oct \\
\hline IRAS $04296+3429 \ldots \ldots$ & 042940.63 & +342954.41 & $\ldots \pm 0.32$ & $\ldots$ & -62 & 0.048 & 2.50 & 2001 Oct \\
\hline IRAS $17150-3224 \ldots \ldots$ & 171504.30 & -322413.05 & $\ldots \pm 0.55$ & $\ldots$ & +26 & 0.081 & 2.50 & $2001 \mathrm{Jul}$ \\
\hline IRAS $17441-2411 \ldots \ldots$ & 174409.71 & -241148.46 & $\ldots \pm 0.70$ & $\ldots$ & +8 & 0.104 & 2.50 & $2001 \mathrm{Jul}$ \\
\hline IRAS $20000+3239 \ldots \ldots$ & 200002.71 & +323907.16 & See text & See text & +14 & 0.037 & 2.50 & 2001 Oct \\
\hline IRAS $21318+5631 \ldots \ldots$ & 213150.01 & +563113.23 & $\ldots \pm 0.78$ & $\ldots$ & +3 & 0.115 & 2.50 & 1999 Sep \\
\hline IRAS $22223+4327 \ldots \ldots$ & 222223.66 & +432756.51 & $\ldots \pm 0.35$ & $\ldots$ & -30 & 0.052 & 2.50 & 2001 Oct \\
\hline IRAS $22272+5435 \ldots \ldots$ & 222713.48 & +543543.80 & $\ldots \pm 0.56$ & $\cdots$ & -28 & 0.083 & 2.50 & 1999 Aug \\
\hline IRAS $22574+6609 \ldots \ldots$ & 225725.01 & +660942.45 & $\ldots \pm 0.27$ & $\ldots$ & -65 & 0.040 & 2.50 & 2001 Oct \\
\hline IRAS $23166+1655 \ldots \ldots$ & 231642.35 & +165510.13 & $\ldots \pm 0.53$ & $\ldots$ & -31 & 0.079 & 2.50 & 1999 Sep \\
\hline IRAS $23304+6147 \ldots \ldots$ & 233026.53 & +614715.31 & $\ldots \pm 0.75$ & $\ldots \ldots \ldots$ & -16 & 0.112 & 2.50 & 1999 Sep \\
\hline
\end{tabular}

Nоте.--Units of right ascension are hours, minutes, and seconds, and units of declination are degrees, arcminutes, and arcseconds.

(FWHM) of 10 ".8 and a main beam efficiency $\left(\eta_{\mathrm{MB}}\right)$ of 0.52 at $492 \mathrm{GHz}$ during this period. Common user receiver $\mathrm{RxW}$ was used in a single sideband mode with two diagonal polarization channels. The system temperature was $1000-5000 \mathrm{~K}$ depending on weather and source elevation. The observations were made by beamswitching at $1 \mathrm{~Hz}$ with a beam throw of $120^{\prime \prime}$ or $180^{\prime \prime}$ in azimuth. The pointing was checked every $60-90$ minutes, and the pointing errors were about $2^{\prime \prime}$ or less in azimuth and elevation. The back end was the digital autocorrelation spectrometer with an instantaneous bandwidth of $500 \mathrm{MHz}$ and a channel interval of $625 \mathrm{kHz}$ (a frequency resolution of $756 \mathrm{kHz}$ ). The data were originally represented as the antenna temperature $T_{A}^{*}$, which had been corrected for antenna losses and atmospheric attenuation. The antenna temperature was later converted to the main beam temperature $T_{\mathrm{MB}}$ with $T_{\mathrm{MB}}=T_{A}^{*} / \eta_{\mathrm{MB}}$. In this paper, most of the intensities will be expressed as $T_{\mathrm{MB}}$. The calibration uncertainty is estimated to have been $10 \%$ throughout this observing program. The sources observed in this survey are listed in Table 1.

We also obtained additional $\mathrm{C}$ I observations of NGC 7027 and AFGL 2688 from the JCMT public data archive at the Canadian Astronomical Data Centre (CADC). The observations were made using the common user receiver $\mathrm{RxC} 2$ and the Canadian Acousto-optical Spectrometer on 1993 June 3. The main beam efficiency was 0.52 (van der Veen et al. 1998).

The JCMT archives at the CADC were also searched for CO observations for NGC 6302 and IRAS $21282+5050$. For NGC 6302, CO $(J=3-2,2-1)$ data and ${ }^{13} \mathrm{CO}(2-1)$ data were obtained from the CADC. For IRAS $21282+5050, \mathrm{CO}(4-3,3-2,2-1)$ data and ${ }^{13} \mathrm{CO}(3-2,2-1)$ data were obtained from the CADC. We assume $\eta_{\mathrm{MB}}=0.52(460 \mathrm{GHz}), 0.63(345 \mathrm{GHz})$, and $0.69(230 \mathrm{GHz})$ for the archival CO data.

The data including archival data were later processed (several channels were binned to reduce the noise level and linear baselines were removed). The rms noise levels $\sigma_{\mathrm{MB}}$ in
Table 1 were determined for the reduced frequency resolution $\Delta \nu$, which are also given in Table 1.

\section{RESULTS}

C I was detected in NGC 6302, IRAS 21282+5050, NGC 7027, and AFGL 2688. The detections in NGC 6302 and IRAS $21282+5050$ are the first in these sources, with NGC 6302 representing the first detection of $\mathrm{C}_{\mathrm{I}}$ in a post-AGB object with $\mathrm{O}>\mathrm{C}$. The detections in AFGL 2688 and NGC 7027 confirm the previous observations by Young (1997) and Young (1994), respectively. The observed spectra are presented in Figure 1, and the line intensities are listed in Table 1.

For the nondetections (entries in Table 1 without a $T_{\mathrm{MB}}$ value), the $V_{\text {LSR }}$ values indicate the velocities (mostly from $\mathrm{CO}$ observations) at which the $\mathrm{C}$ I line was searched for. The sources with negative results are either extreme carbon stars or PPNe with cool central stars. The $1 \sigma$ uncertainties in integrated intensity for the negative results in Table 1 were estimated with an assumed expansion velocity of $15 \mathrm{~km} \mathrm{~s}^{-1}$ common to all the negative results. The $\mathrm{C}$ I spectrum in the direction of IRAS $20000+3239$ is contaminated by narrow emission at the reference positions. The published $\mathrm{CO}$ spectra by Omont et al. (1993) (CO $J=2-1$ ) and by Knapp et al. (2000) (CO $J=4-3)$ show narrow depressions similar to the $\mathrm{C}$ I spectrum. However, the $\mathrm{C}$ i spectrum lacks the broad emission $\left(0<V_{\mathrm{LSR}}<+30 \mathrm{~km} \mathrm{~s}^{-1}\right)$ seen in the $\mathrm{CO}$ spectra.

The two new detections in the present survey bring the number of PNe with detected C I to five (Young 1997). The number of carbon stars or post-AGB stars with $\mathrm{C}$ I detection remains at six (Knapp et al. 2000).

The two measurements for NGC 7027, eight years apart and with different receivers, are consistent (See Table 1). The spectrum (Fig. 1) shows a double-peaked profile, suggesting that the source is resolved by the 10".8 JCMT beam. A spectrum obtained in 1992 by Young (1994) shows a flattop profile when observed by the CSO with a beam of $15^{\prime \prime}$. While this suggests that the source is unresolved, a five- 


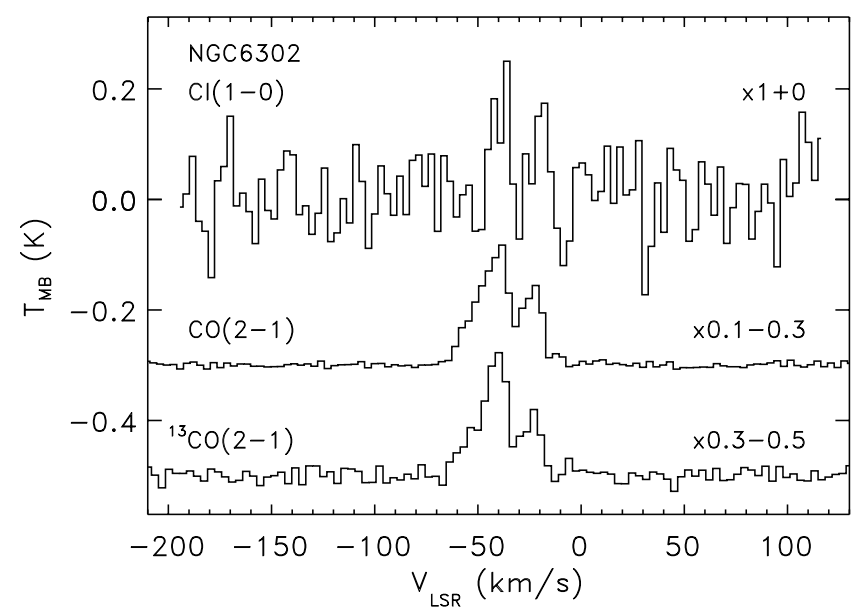

FIG. $1 a$

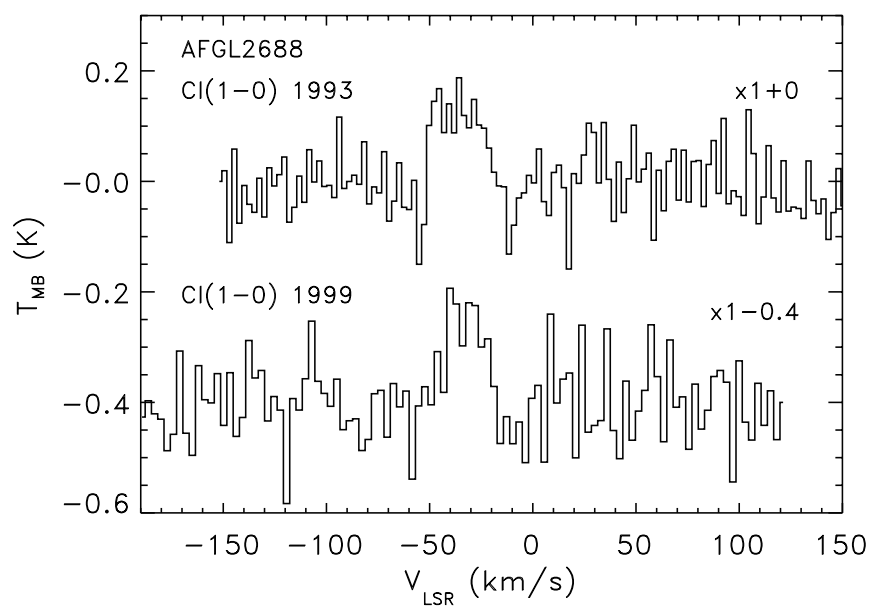

FIG. $1 c$

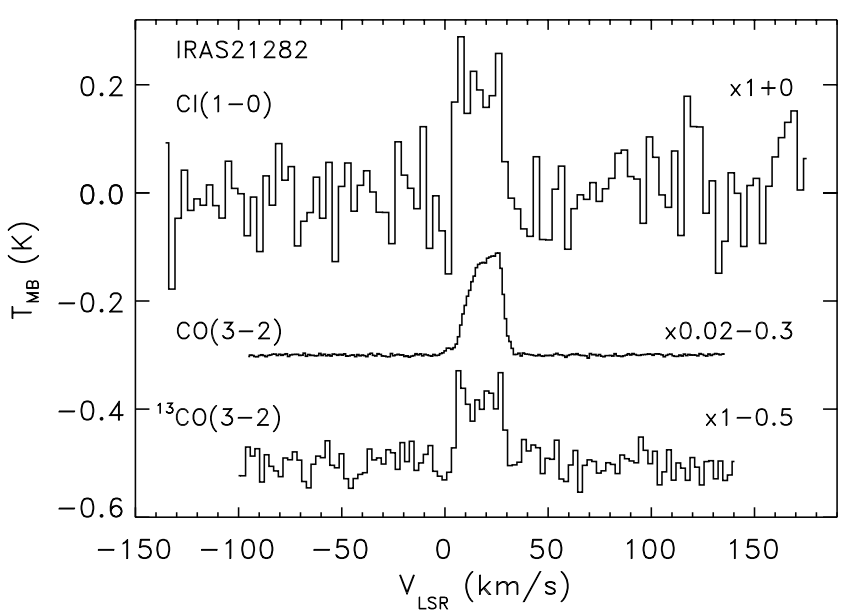

FIG. $1 b$

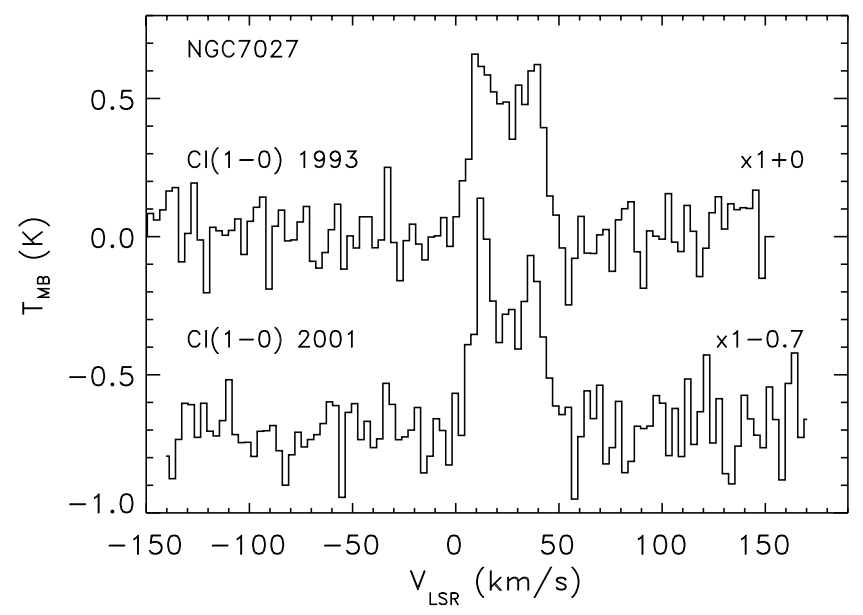

FIG. $1 d$

FIG. 1.-Observed C I $\left({ }^{3} P_{1}-3 P_{0}\right)$ spectra in $(a)$ NGC 6302, (b) IRAS 21282+5050, (c) AFGL 2688, and $(d)$ NGC 7027. For NGC 6302, CO (2-1) and ${ }^{13}$ CO (2-1) spectra are shown at reduced intensity scales for comparison. For IRAS $21282, \mathrm{CO}(3-2)$ and ${ }^{13} \mathrm{CO}(3-2)$ spectra are shown at reduced scales.

point map with one beamwidth shifts from the center position suggests that NGC 7027 is extended (Young 1994).

For AFGL 2688, the two measurements show a discrepancy by a factor of about 2 . We consider the discrepancy as a result of poor signal-to-noise ratios and poor baselines in both spectra taken in 1993 and 1999. The straight average of the two measurements of $\int T_{\mathrm{MB}} d V$ for AFGL 2688 in Table 1 is $5.48 \mathrm{~K} \mathrm{~km} \mathrm{~s}^{-1}$, which is close to $5.1 \mathrm{~K} \mathrm{~km} \mathrm{~s}^{-1}$ by Young (1997). For each of NGC 7027 and AFGL 2688, the straight average of two measurements in Table 1 is adopted for further analysis.

\section{ANALYSIS}

\subsection{Planetary Nebulae}

The observed $\mathrm{C}_{\mathrm{I}}(1-0)$ integrated intensity is converted to the beam-averaged $\mathrm{C}$ I column density $N(\mathrm{C}$ I $)$ by $N\left({ }^{3} \mathrm{P}_{1}\right)$ $\left[\mathrm{cm}^{-2}\right]=5.94 \times 10^{15} \int T_{\mathrm{MB}}\left({ }^{3} P_{1}{ }^{3} P_{0}\right) d V\left[\mathrm{~K} \mathrm{~km} \mathrm{~s}^{-1}\right]$ and $N\left(\mathrm{C}_{\mathrm{I}} \mathrm{I}\right)\left[\mathrm{cm}^{-2}\right]=\frac{1}{3}\left[\exp \left(23.6 / T_{\text {ex }}\right)+3+\exp \left(-38.8 / T_{\mathrm{ex}}\right)\right]$ $\times N\left({ }^{3} \mathrm{P}_{1}\right)\left[\mathrm{cm}^{-2}\right]$ (Bachiller et al. 1994; Phillips \& Huggins 1981 ). We assume $T_{\mathrm{ex}}=20 \mathrm{~K}$, but the correction for the $J=0$ and 2 levels is not very sensitive to the assumed $T_{\mathrm{ex}}$ for $15 \mathrm{~K}<T_{\mathrm{ex}}<800 \mathrm{~K}$ (Huggins et al. 1994; Bachiller et al. 1994; Young et al. 1997). The estimated C I column den- sities are given in Table 2. Also given in Table 2 are the total numbers of neutral carbon atoms in the volume subtended by the 10 "' 8 beam of the JCMT at distance $D(\mathrm{kpc})$.

The significance of the amount of detected $\mathrm{C}$ i becomes clearer when it is compared with that of molecular material. In order to estimate the relative amount of $\mathrm{C}_{\mathrm{I}}$ in $\mathrm{PNe}$, we take the ratio of column densities of $\mathrm{C}$ I and $\mathrm{CO}$. The beam-averaged column density of $\mathrm{CO}, N(\mathrm{CO})$, is estimated as follows. If a ${ }^{13} \mathrm{CO}(J=3-2)$ observation is available, we assume $N(\mathrm{CO})=20 N\left({ }^{13} \mathrm{CO}\right)$ (Young 1997). (See below for discussions on the ${ }^{12} \mathrm{CO} /{ }^{13} \mathrm{CO}$ ratio.) The beam-averaged column density of ${ }^{13} \mathrm{CO}$ is estimated by $N\left({ }^{13} \mathrm{CO}\right)\left[\mathrm{cm}^{-2}\right]=5.08 \times 10^{12} T_{\mathrm{ex}}$ $\times \exp \left(+31.73 / T_{\mathrm{ex}}\right) \int T_{\mathrm{MB}}^{13}(3-2) d V\left[\mathrm{~K} \mathrm{~km} \mathrm{~s}^{-1}\right]$ under the assumption that the ${ }^{13} \mathrm{CO}$ levels are thermalized at $T_{\mathrm{ex}}$ and the rotational lines are optically thin. We adopt $T_{\mathrm{ex}}=20 \mathrm{~K}$. Bachiller et al. (1997) observed a PPN and six $\mathrm{PNe}$ in six molecules (two transitions each) and estimated the representative excitation temperature to be 25 $\mathrm{K}$ common to the seven sources and six molecules. If a ${ }^{13} \mathrm{CO}(J=2-1)$ observation is available, the ${ }^{13} \mathrm{CO}$ column density is estimated by $N\left({ }^{13} \mathrm{CO}\right)\left[\mathrm{cm}^{-2}\right]=1.14 \times 10^{13} T_{\mathrm{ex}}$ $\times \exp \left(+15.87 / T_{\mathrm{ex}}\right) \int T_{\mathrm{MB}}^{13}(2-1) d V\left[\begin{array}{lll}\mathrm{K} & \mathrm{km} & \mathrm{s}^{-1}\end{array}\right]$ (Young 1997). 
TABLE 2

C i Abundances in Planetary Nebulae

\begin{tabular}{|c|c|c|c|c|c|c|}
\hline Source & $\begin{array}{c}N(\mathrm{C} \mathrm{I}) \\
\left(\times 10^{16} \mathrm{~cm}^{-2}\right)\end{array}$ & $N(\mathrm{C} \mathrm{I}) / N(\mathrm{CO})$ & $\begin{array}{l}T_{\text {eff }} \\
(\mathrm{K})\end{array}$ & Chemistry & $\begin{array}{c}N(\mathrm{C} \mathrm{I}) \Delta S_{\mathrm{MB}} \\
{\left[\times 10^{51}(D / \mathrm{kpc})^{2}\right]}\end{array}$ & References (for $\mathrm{C}$; ; for $\mathrm{CO}$ ) \\
\hline \multirow[t]{3}{*}{ IRC $+10216 \ldots \ldots \ldots \ldots \ldots$} & \multirow[t]{3}{*}{5.4} & 0.04 & \multirow[t]{3}{*}{1250} & \multirow[t]{3}{*}{$\mathrm{C}>\mathrm{O}>\mathrm{N}$} & & 10,$6 ; 7,10 \mathrm{CSO}^{13} \mathrm{CO}(2-1)$ \\
\hline & & 0.02 & & & & $2 ; 2 \mathrm{CSO}^{13} \mathrm{CO}(2-1)$ \\
\hline & & 0.1 & & & & 4; 4 IRAM CO (2-1) \\
\hline \multirow[t]{2}{*}{ 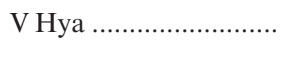 } & \multirow[t]{2}{*}{3.4} & 0.40 & \multirow[t]{2}{*}{2650} & \multirow[t]{2}{*}{$\mathrm{C}>\mathrm{O}>\mathrm{N}$} & & 5,$6 ; 7,5 \mathrm{CSO} \mathrm{CO}(4-3)$ \\
\hline & & 0.3 & & & & $5 ; 5 \mathrm{CSO} \mathrm{CO}(4-3)$ \\
\hline \multirow[t]{2}{*}{ AFGL $2688 \ldots \ldots \ldots \ldots . . . . . .}$. & \multirow[t]{2}{*}{7.6} & 0.067 & \multirow[t]{2}{*}{6500} & \multirow[t]{2}{*}{$\mathrm{C}>\mathrm{O}>\mathrm{N}$} & \multirow[t]{5}{*}{2.2} & $1 ; 7,9$ IRAM ${ }^{13} \mathrm{CO}(2-1)$ \\
\hline & & 0.07 & & & & $2 ; 2$ IRAM ${ }^{13} \mathrm{CO}(2-1)$ \\
\hline \multirow{3}{*}{ IRAS $07134+1005 \ldots \ldots$} & \multirow[t]{3}{*}{3.9} & 1.30 & \multirow[t]{3}{*}{6500} & \multirow[t]{3}{*}{$\mathrm{C}>\mathrm{O}>\mathrm{N}$} & & 5,$6 ; 7,5$ CSO CO $(4-3)$ \\
\hline & & 0.4 & & & & $5 ; 5 \mathrm{CSO} \mathrm{CO}(4-3)$ \\
\hline & & 1.85 & & & & 5, 6; 7, 9 IRAM CO (2-1) \\
\hline AFGL $618 \ldots \ldots \ldots \ldots \ldots . . . . . .$. & 25.0 & 0.7 & 30000 & $\mathrm{C}>\mathrm{O}>\mathrm{N}$ & & $2 ; 2$ IRAM ${ }^{13} \mathrm{CO}(2-1)$ \\
\hline \multirow[t]{3}{*}{ IRAS $21282+5050 \ldots \ldots$} & \multirow[t]{3}{*}{7.1} & 0.53 & \multirow[t]{3}{*}{$\sim 30000$} & \multirow[t]{3}{*}{$\mathrm{C}>\mathrm{O}>\mathrm{N}$} & \multirow[t]{3}{*}{2.1} & $1 ; 7,3$ IRAM CO (2-1) \\
\hline & & 0.26 & & & & 1; 8 JCMT CO (3-2) \\
\hline & & 0.37 & & & & 1; 8 JCMT CO (4-3) \\
\hline \multirow[t]{3}{*}{ 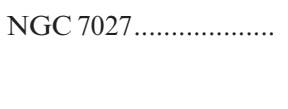 } & \multirow[t]{3}{*}{28.7} & 1.64 & \multirow[t]{3}{*}{200000} & \multirow[t]{3}{*}{$\mathrm{C}>\mathrm{O}>\mathrm{N}$} & \multirow[t]{3}{*}{8.5} & $1 ; 7,9$ IRAM ${ }^{13} \mathrm{CO}(2-1)$ \\
\hline & & 0.91 & & & & $1 ; 7 \mathrm{JCMT}{ }^{13} \mathrm{CO}(3-2)$ \\
\hline & & 0.5 & & & & $2 ; 2$ IRAM ${ }^{13} \mathrm{CO}(2-1)$ \\
\hline \multirow[t]{3}{*}{ 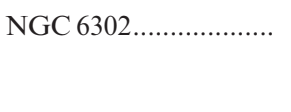 } & \multirow[t]{3}{*}{4.5} & 1.79 & \multirow[t]{3}{*}{380000} & \multirow[t]{3}{*}{$\mathrm{N}>\mathrm{O}>\mathrm{C}$} & \multirow[t]{7}{*}{1.3} & $1 ; 8 \mathrm{JCMT}$ CO $(2-1)$ \\
\hline & & 0.99 & & & & $1 ; 8$ JCMT CO (3-2) \\
\hline & & 0.28 & & & & $1 ; 8$ JCMT ${ }^{13} \mathrm{CO}(2-1)$ \\
\hline 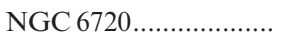 & 13. & 10. & 110000 & $\mathrm{C}>\mathrm{O}>\mathrm{N}$ & & $2 ; 2$ IRAM ${ }^{13} \mathrm{CO}(2-1)$ \\
\hline NGC $7293 \ldots \ldots \ldots \ldots \ldots$ & 1.2 & 6. & 90000 & $\mathrm{C}>\mathrm{O}>\mathrm{N}$ & & $2 ; 2$ IRAM ${ }^{13} \mathrm{CO}(2-1)$ \\
\hline \multirow[t]{2}{*}{ 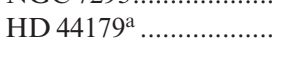 } & 2.7 & 4.4 & 25000 & $\mathrm{C}>\mathrm{O}>\mathrm{N}$ & & 5,$6 ; 7 \mathrm{CSO} \mathrm{CO}(4-3)$ \\
\hline & & 13. & & & & $5 ; 5 \mathrm{CSO} \mathrm{CO}(4-3)$ \\
\hline
\end{tabular}

\footnotetext{
a Object of uncertain evolutionary status.

ReFERENCES.- (1) This paper; (2) Young 1997; (3) Likkel et al. 1988; (4) van der Veen et al. 1998; (5) Knapp et al. 2000; (6) our conversion from published C I observations; (7) our conversion from published CO observations; (8) our CO observations from the JCMT archives; (9) Loup et al. 1993; (10) Keene et al. 1993.
}

We have also estimated $N(\mathrm{CO})$ directly from available $\mathrm{CO}$ observations with the optically thin assumption at a common $T_{\text {ex }}$, because (1) reliable ${ }^{13} \mathrm{CO}$ observations are not always available, and (2) the ${ }^{12} \mathrm{CO} /{ }^{13} \mathrm{CO}$ abundance ratio likely significantly varies from source to source. The conversion formula from the integrated intensity of a $\mathrm{CO}$ rotational line to $N(\mathrm{CO})$ is the same as those for ${ }^{13} \mathrm{CO}$ given above except for constants arising from different molecular constants and is not repeated here (see, for example, Hasegawa \& Mitchell 1995 and Mitchell, Hasegawa, \& Schella 1992). Again, $T_{\mathrm{ex}}=20 \mathrm{~K}$ is assumed. In addition to published data, $\mathrm{CO}$ observations from the JCMT archives were utilized.

The estimated $N(\mathrm{C} \mathrm{I}) / N(\mathrm{CO})$ ratios are given in Table 2. Independent estimates for the same sources and for other post-AGB sources by Young (1997), Knapp et al. (2000), and van der Veen et al. (1998) are also given for comparison. In addition, on the basis of the published $\mathrm{C} \mathrm{I}$ and $\mathrm{CO}$ observations, we have made our estimates in Table 2 for $N(\mathrm{C} \mathrm{I})$ and $\mathrm{C} \mathrm{I} / \mathrm{CO}$ for other sources (not in Table 1) with the method described above. The last column in Table 2 indicates the method of $N(\mathrm{CO})$ estimation (the telescope and the $\mathrm{CO}$ line used). The $N(\mathrm{CO})$ estimates are more uncertain than the $N(\mathrm{C}$ I $)$ estimates themselves, depending on the beam size, the transition, and the method of conversion from an observed value to $N(\mathrm{CO})$. The estimated $N(\mathrm{CO})$ for NGC 6302 from $\mathrm{CO}$ observations (not ${ }^{13} \mathrm{CO}$ ) may be lower than an actual value, whereas $N(\mathrm{CO})$ from the ${ }^{13} \mathrm{CO}$ observation gives an upper limit to $N(\mathrm{CO})$ (a lower limit to the $\mathrm{C}$ I/CO abundance ratio). For our ${ }^{13} \mathrm{CO}(2-1)$ observation in NGC 6302 (Fig. 1a) indicates that the $\mathrm{CO}(2-1) /{ }^{13} \mathrm{CO}(2-$
1) intensity ratio is unusually low at 3 for a $\mathrm{PN}$, and that the corresponding abundance ratio may be significantly lower than 20 assumed in the present analysis. The $N(\mathrm{CO})$ estimate for IRAS $21282+5050$ in Table 2 should not be much lower than the actual value, because the ${ }^{13} \mathrm{CO}$ lines are unusually weak [about $1 / 50(J=3-2)$ to $1 / 100(J=1-0)$ of the $\mathrm{CO}$ lines as can be seen in Figure $1 b$ and in Likkel et al. 1988] and the CO lines are likely optically thin. The ${ }^{12} \mathrm{C} /{ }^{13} \mathrm{C}$ ratio and the possible deviation of ${ }^{12} \mathrm{CO} /{ }^{13} \mathrm{CO}$ from the isotopic ratio are serious sources of uncertainty in $N(\mathrm{CO})$ for other objects, too. Young (1997) refers to various estimates for ${ }^{12} \mathrm{C} /{ }^{13} \mathrm{C}$ ranging from 8 to 40 . For evolved $\mathrm{PNe}$, Bachiller et al. (1997) estimate $10 \leq \mathrm{CO} /{ }^{13} \mathrm{CO} \leq 25$. In a recent CO study, Balser, McMullin, \& Wilson (2002) find $2 \leq \mathrm{CO} /{ }^{13} \mathrm{CO} \leq 31$. Hasegawa \& Kwok (2001), however, have determined $\mathrm{HCO}^{+} / \mathrm{H}^{13} \mathrm{CO}^{+}=40$ for NGC 7027. For IRC +10216, Kahane et al. (1988) have reliably determined ${ }^{12} \mathrm{C} /{ }^{13} \mathrm{C}=47$. Therefore, the individual values for $N(\mathrm{C} \mathrm{I}) /$ $N(\mathrm{CO})$ in Table 2 carry uncertainties by factors of $2-4$.

In Table 2, the discrepancies in $\mathrm{C} \mathrm{I} / \mathrm{CO}$ estimate for the same source reach a factor of 3-5 in the worst cases. The major source of the discrepancies in $\mathrm{C}$ I/ $\mathrm{CO}$ is the $\mathrm{CO}$ transition used and the method of conversion to $N(\mathrm{CO})$. Our conversion method tends to yield a higher $N(\mathrm{CO})$ estimate for a higher rotational line under the same $T_{\mathrm{ex}}$. (The beam size is not the only reason for this, as can be seen in NGC 7027 in Table 2.) Conversion from a CO line yields a lower estimate of $N(\mathrm{CO})$ than from a ${ }^{13} \mathrm{CO}$ line under our assumption of $\tau<1$, obviously because of the opacity effect. Therefore, an estimate of $\mathrm{C} \mathrm{I} / \mathrm{CO}$ in isolation should be taken with some caution. Also, comparison of estimates of 
$\mathrm{C} \mathrm{I} / \mathrm{CO}$ for different objects from different reports needs a greater caution for a systematic discrepancy. A more uniform or standardized set of $\mathrm{CO}$ or ${ }^{13} \mathrm{CO}$ observations will be desirable in the future as pointed out by Knapp et al. (2000). In addition, $\mathrm{PNe}$ and $\mathrm{PPNe}$ may require different methods to analyze (Knapp et al. 2000). The present $\mathrm{C}$ I/CO estimates in Table 2 are nevertheless useful as relative indicators of the (neutral) atomic content versus the molecular content in the post-AGB objects, and the $\mathrm{C}$ I/CO ratios in Table 2 tend to be larger for the objects in a later evolutionary stage.

The entries in Table 2 are arranged in the order of their evolutionary stages (not stellar temperature) from the AGB to $\mathrm{PN}$ phase, although the order is subjective. The two new detections (NGC 6302 and IRAS 21282+5050) and the two independent observations in the present work lend support to the trend first recognized by Young (1997) that C I/CO increases with the evolutionary stage. All the listed sources except NGC 6302 are carbon-rich sources. NGC 6302 is classified as extreme type I (Perinotto 1991), and HCN has been detected (Sahai, Wooten, \& Clegg 1993). The C I/CO ratio in NGC 6302 does not deviate from the trend seen in carbon-rich PNe.

We have placed V Hya between IRC +10216 and AFGL 2688 in evolutionary stage. This is an unusual carbon star with a fast $\left(200 \mathrm{~km} \mathrm{~s}^{-1}\right)$ bipolar outflow (Knapp et al. 2000 and references therein). Knapp, Jorissen, \& Young (1997) and Kahane et al. (1996) both argue that V Hya has just developed the bipolar flow. We regard the high $\mathrm{C}_{\mathrm{I}} / \mathrm{CO}$ ratio in V Hya as an exception caused by dynamical effects such as a shock (Knapp et al. 2000).

The estimated amount of $\mathrm{C}$ I in NGC 7027 is $N\left(\mathrm{C}_{\mathrm{I}}\right)=3 \times 10^{17} \mathrm{~cm}^{-2}$ and $N\left(\mathrm{C}_{\mathrm{I}}\right) \Delta S_{\mathrm{MB}}=7 \times 10^{51}$ atoms with $D=0.93 \mathrm{kpc}($ Volk \& Kwok 1997) in the present work.
These estimates are significantly lower than model predictions, $N(\mathrm{CI})=3 \times 10^{18} \mathrm{~cm}^{-2}$ and $N(\mathrm{C}$ I $) \Delta S_{\mathrm{PDR}}=3 \times 10^{52}$ atoms, by Hasegawa, Volk, \& Kwok (2000).

\subsection{Carbon Stars and Protoplanetary Nebulae}

The rest of the objects in Table 1 are extreme carbon stars and PPNe. The C I (1-0) line was not detected in any of the stellar sources. Table 3 gives $3 \sigma$ upper limits in integrated intensity $I\left(\mathrm{C}_{\mathrm{I}}\right)=\int T_{\mathrm{MB}}\left(\mathrm{C}_{\mathrm{I}} 1-0\right) d V$ for these sources. These upper limits (or statistical uncertainties in Table 1) are comparable to those by Knapp et al. (2000) and are improvements over those by van der Veen et al. (1998) by about a factor of 2, although there are few common stellar sources in this paper and the other two. The current upper limits are still insufficient to quantitatively study the $\mathrm{C}$ I contents in PPNe. This can be seen by comparing the $I(\mathrm{C} \mathrm{I})$ upper limits with observed $I(\mathrm{CO})$. $\mathrm{CO}$ observations in the sources are listed in Table 3. Wherever available, published CO (2-1) observations with the IRAM $30 \mathrm{~m}$ telescope (Loup et al. 1993) are listed for uniform comparison. Otherwise, any available $\mathrm{CO}$ observations have been scaled to $\int T_{\mathrm{MB}} d V[\mathrm{CO}$ (2-1), IRAM] under the assumptions that the $\mathrm{CO}$ lines are optically thick and thermalized at $20 \mathrm{~K}$ and that the source is sufficiently small. The scaled $I(\mathrm{CO})$ values are given in parentheses in Table 3. The upper limits to $I(\mathrm{C} \mathrm{I}) / I(\mathrm{CO})$ for our sources are $0.014-0.114$.

For comparison, the $\mathrm{C}$ I to $\mathrm{CO}$ intensity ratios are listed in Table 3 for representative stellar and PPN sources. IRC +10216, V Hya, and AFGL 2688 represent objects in the preionization phase (AGB and $\mathrm{PPN}$ ), and their $\mathrm{I}(\mathrm{C} \mathrm{I}) /$ $I(\mathrm{CO})$ ratios range from 0.004 to 0.024 . The detection limits in the present study only marginally reach these levels. For AFGL 618, where the central star is just beginning to photoionize the envelope (Kwok \& Bignell 1984),

TABLE 3

UPPER LIMITS TO C I EMISSION

\begin{tabular}{|c|c|c|c|c|}
\hline Source & $\begin{array}{c}I\left(\mathrm{C}_{\mathrm{I}} 1-0\right) \\
\left(\mathrm{K} \mathrm{km} \mathrm{s}^{-1}\right)\end{array}$ & $\begin{array}{l}I(\mathrm{CO} 2-1) \\
\left(\mathrm{K} \mathrm{km} \mathrm{s}^{-1}\right)\end{array}$ & $I\left(\mathrm{C}_{\mathrm{I}}\right) / I(\mathrm{CO})$ & $\begin{array}{c}\text { References } \\
\text { (for } \mathrm{C} \text {; f for } \mathrm{CO} \text { ) }\end{array}$ \\
\hline \multicolumn{5}{|c|}{ Nondetection Sources } \\
\hline IRAS $02229+6208 \ldots \ldots$ & $<1.29$ & $(21.2)$ & $<0.061$ & $1 ; 2 \mathrm{JCMT}$ CO (3-2) \\
\hline IRAS $04296+3429 \ldots \ldots$ & $<0.94$ & 8.30 & $<0.114$ & $1 ; 3$ \\
\hline IRAS $17150-3224 \ldots \ldots$. & $<1.64$ & $\ldots$ & $\ldots$ & 1 \\
\hline IRAS $17441-2411 \ldots \ldots$ & $<2.11$ & $(31.3)$ & $<0.067$ & $1 ; 2 \mathrm{JCMT} \mathrm{CO}(3-2)$ \\
\hline IRAS $20000+3239 \ldots \ldots$ & $\ldots$ & 9.40 & $\ldots$ & $1 ; 3$ \\
\hline IRAS $21318+5631 \ldots \ldots$ & $<2.34$ & $(100.3)$ & $<0.023$ & $1 ; 7$ JCMT CO $(2-1)$ \\
\hline IRAS $22223+4327 \ldots \ldots$ & $<1.05$ & 12.3 & $<0.086$ & $1 ; 3$ \\
\hline IRAS $22272+5435 \ldots \ldots$ & $<1.68$ & 80.5 & $<0.021$ & $1 ; 3$ \\
\hline IRAS $22574+6609 \ldots \ldots$ & $<0.82$ & 11.0 & $<0.074$ & $1 ; 3$ \\
\hline IRAS $23166+1655 \ldots \ldots$ & $<1.60$ & 113.0 & $<0.014$ & $1 ; 3$ \\
\hline IRAS $23304+6147 \ldots \ldots$ & $<2.26$ & 25.0 & $<0.090$ & $1 ; 3$ \\
\hline \multicolumn{5}{|c|}{ Representative (Post-)AGB Sources } \\
\hline IRC $+10216 \ldots \ldots \ldots \ldots \ldots$ & 3.9 & 977 & 0.004 & 6,$9 ; 3$ \\
\hline 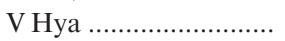 & 2.45 & (103) & 0.024 & $5 ; 8 \operatorname{CSO} \mathrm{CO}(2-1)$ \\
\hline AFGL $2688 \ldots \ldots \ldots \ldots \ldots$ & 5.5 & 312 & 0.018 & 1,$4 ; 3$ \\
\hline AFGL $618 \ldots \ldots \ldots \ldots \ldots \ldots$ & 17.8 & 250 & 0.071 & $4 ; 3$ \\
\hline IRAS $07134+1005 \ldots \ldots$ & 2.82 & 44 & 0.064 & $5 ; 3$ \\
\hline 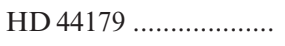 & 1.92 & (5.6) & 0.34 & $5 ; 3$ IRAM CO (1-0) \\
\hline
\end{tabular}

REFERENCES.- (1) This paper; (2) our CO(3-2) observation (unpublished); (3) Loup et al. 1993; (4) Young 1997; (5) Knapp et al. 2000; (6) van der Veen et al. 1998; (7) Volk, Kwok, \& Woodsworth 1993; (8) Knapp et al. 1997; (9) Keene et al. 1993. 
$I(\mathrm{C} \mathrm{I}) / I(\mathrm{CO}) \sim 0.07$. The upper limits in this paper are mostly similar to this level.

Conversely, the present study supports the picture that the relative amount of gas-phase neutral atomic carbon is generally low in carbon-rich post-AGB stars, consistent with predictions from chemical models. None in our source in Table 3 shows $I(\mathrm{C} \mathrm{I}) / I(\mathrm{CO})$ reaching the level of $\geq 0.1$ seen in young PNe (AFGL 618) or the peculiar binary system HD 44179 (the "Red Rectangle").

Among the observed sources are a number of bipolar PPNe with morphologies strikingly similar to AFGL 2688 (IRAS 17150-3224, Kwok, Su, \& Hrivnak 1998; IRAS 17441-2411, Su et al. 1998). Since these sources are all relatively small (with angular sizes of a few arcsec or less), the observations of these objects may suffer from beam dilution. Even if these sources may have $I(\mathrm{C} \mathrm{I}) / I(\mathrm{CO})$ similar to AFGL 2688 ( 0.0175), they may be too distant to detect $\mathrm{C}_{\mathrm{I}}(1-0)$ at this level of abundance.

\section{INDIVIDUAL OBJECTS}

Among the five PNe detected in C I (1-0), NGC 6720 and NGC 7293 do not have as large an infrared excess or as thick a circumstellar envelope as NGC 7027. In this regard, the new detections NGC 6302 and IRAS $21282+5050$ are more similar to NGC 7027. Here are some brief notes on the comparison of these two objects to NGC 7027.

\subsection{NGC 6302}

NGC 6302 is a high-excitation PN with an extreme bipolar morphology. The presence of emission lines with excitation potentials exceeding $200 \mathrm{eV}$ suggests that the central star is of very high temperature. Estimates of the central star temperature range from 250,000 K (Casassus, Roche, \& Barlow 2000), 380,000 K (Pottasch et al. 1996), to 450,000 K (Lame \& Ferland 1991). NGC 6302 has been classified as type I (Perinotto 1991) based on its chemical abundance and morphology, as are the bipolar PNe NGC 2440 and NGC 2346. The elemental abundances for NGC 6302 are $[\mathrm{C} / \mathrm{H}]=1 \times 10^{-4},[\mathrm{O} / \mathrm{H}]=5 \times 10^{-4},[\mathrm{~N} / \mathrm{H}]=8.5 \times 10^{-4}$ (Perinotto 1991). Neutral atomic hydrogen (H I) has been detected in NGC 6302 as absorption in the $21 \mathrm{~cm}$ line (Rodríguez \& García-Barreto 1984; Rodríguez, GarcíaBarreto, \& Gómez 1985), with a total H i column density $N\left(\mathrm{H}_{\mathrm{I}}\right)$ of $4 \times 10^{+20} \mathrm{~cm}^{-2}$. The nominal $\mathrm{C} \mathrm{I} / \mathrm{H} \mathrm{I}$ ratio is $N\left(\mathrm{C}_{\mathrm{I}}\right) / N\left(\mathrm{H}_{\mathrm{I}}\right)=1.1 \times 10^{-4}$, close to the elemental abundance ratio, in NGC 6302.

The estimated $\mathrm{C}$ I/CO abundance ratio is $1-2$ for NGC 6302 , although the ratio may be lower by a factor of $2-3$ because of unknown optical depths for the CO lines. As mentioned in $\S 4.1$, NGC 6302 has an unusually low value of 3 for $I(\mathrm{CO}) / I\left({ }^{13} \mathrm{CO}\right)$. The $\mathrm{CO} /{ }^{13} \mathrm{CO}$ abundance ratio is likely much lower than 20 assumed in the present analysis for NGC 6302, and the $\mathrm{Cr} / \mathrm{CO}$ abundance ratio is probably higher than 0.28 given in Table 2. Even if we allow for a $\mathrm{C} \mathrm{I} /$ $\mathrm{CO}$ ratio as low as $0.5, \mathrm{C}$ I/CO in NGC 6302 is close to the values estimated in NGC 7027 and IRAS $21282+5050$, both of which are very young PNe. C I/CO in NGC 6302 is clearly lower than the values in the more evolved nebulae NGC 6720 and NGC 7293. C $\mathrm{r}$ in young PNe is predicted to be produced by photodissociation of $\mathrm{CO}$, and the elemental abundances are not expected to be a deciding factor for $\mathrm{CI} /$ CO. The $\mathrm{C}$ I/CO estimate for NGC 6302 in the present work, in comparison with other $\mathrm{PNe}$, is consistent with the current scenario for $\mathrm{C}$ I production.

\subsection{IRAS $21282+5050$}

IRAS $21282+5050$ is a compact PN with a strong infrared excess (Kwok, Hrivnak, \& Langill 1993). It has a [WC11] central star and shows strong emission in the aromatic hydrocarbon features (Cohen \& Jones 1987). Its carbon-rich nature is also supported by the detection of gas phase molecules $\mathrm{HCN}, \mathrm{CN}$, and $\mathrm{C}_{2} \mathrm{H}$ (T. Hasegawa \& S. Kwok 2003, in preparation). Its small ionized region (Likkel et al. 1994; Meixner et al. 1993) and strong infrared excesses suggest that it is a young PN in an evolutionary state similar to that of NGC 7027 (Meixner et al. 1993; Shibata et al. 1989). Our estimate of 0.5 for $\mathrm{C} \mathrm{I} / \mathrm{CO}$ in this source is close to those found in AFGL 618 and NGC 7027 and further supports the picture that $\mathrm{C} \mathrm{I}$ is produced at the expense of $\mathrm{CO}$.

\section{SUMMARY}

The $492 \mathrm{GHz}$ fine-structure line of $\mathrm{C}$ I was detected for the first time in two $\mathrm{PNe}$, bringing the total number of $\mathrm{PNe}$ detection to five. The new detection includes NGC 6302, representing the first detection of $\mathrm{C}_{\mathrm{I}}$ in an O-rich PN. On the basis of the upper limits and previous detections, we found that the $\mathrm{C}$ I to $\mathrm{CO}$ abundance ratio changes from $\sim 10^{-2}$ in carbon stars, to $\sim 10^{-1}$ in PPNe, to $\sim 10^{0}$ in young $\mathrm{PNe}$, to $\sim 10^{1}$ in evolved $\mathrm{PNe}$. This trend is consistent with chemical models where $\mathrm{C}$ I is produced by the photodissociation of $\mathrm{CO}$. These $\mathrm{C}$ I observations therefore provide useful constraints on photochemistry of the circumstellar envelope during the transition from AGB to PN. As more molecular species are detected at different phases of this transition, a model can be developed to map out the complete chemical network in a circumstellar environment.

We thank H. E. Matthews for observing some of the sources and Ken Young for providing us with his unpublished spectrum of NGC 7027. The JCMT is operated by the Joint Astronomy Centre on behalf of the Particle Physics and Astronomy Research Council of the United Kingdom, the Netherlands Organisation for Scientific Research, and the National Research Council of Canada. The CADC is operated by the Herzberg Institute of Astrophysics, National Research Council of Canada. This work is supported by a grant to S. K. from the Natural Sciences and Engineering Research Council of Canada, and a Killam Fellowship from the Canada Council for the Arts.
Bachiller, R., Forveille, T., Huggins, P. J. \& Cox, P. 1997, A\&A, 324, 1123 Bachiller, R., Huggins, P. J., Cox, P., \& Forveille, T. 1994, A\&A, 281, L93 Balser, D. S., McMullin, J. P., \& Wilson, T. L. 2002, ApJ, 572, 326 Casassus, S., Roche, P. F., \& Barlow, M. J. 2000, MNRAS, 314, 657 Cernicharo, J., et al. 2001, ApJ, 546, L123

Cherchneff, I., \& Barker, R. 1992, ApJ, 394, 703

Cherchneff, I., Glassgold, A. E., \& Mamon, G. A. 1993, ApJ, 410, 188

\section{REFERENCES}

Cohen, M., \& Jones, B. F. 1987, ApJ, 321, L151

Hasegawa, T. I., \& Kwok, S. 2001, ApJ, 562, 824

Hasegawa, T. I., \& Mitchell, G. F. 1995, ApJ, 451, 225

Hasegawa, T. I., Volk, K., \& Kwok, S. 2000, ApJ, 532, 994

Hrivnak, B. J., Volk, K., \& Kwok, S. 2000, ApJ, 535, 275

Huggins, P. J., Bachiller, R., Cox, P., \& Forveille, T. 1994, ApJ, 424, L127 
Kahane, C., Audinos, P., Barnbaum, C., \& Morris, M. 1996, A\&A, 314, 871

Kahane, C., Gomez-Gonzalez, J, Cernicharo, J., \& Guelin, M. 1988, A\&A, 190, 167

Keene, J., Young, K., Phillips, T. G., Buttgenbach, T. H., \& Carlstrom, J. E. 1993, ApJ, 415, L131

Knapp, G. R., Crosas, M., Young, K., \& Ivezic, Z. 2000, ApJ, 534, 324

Knapp, G. R., Jorissen, A., \& Young, K. 1997, A\&A, 326, 318

Kwok, S. 1993, ARA\&A, 31, 63

Kwok, S., \& Bignell, R. C. 1984, ApJ, 276, 544

Kwok, S., Hrivnak, B. J., \& Geballe, T. R. 1995, ApJ, 454, 394

Kwok, S., Hrivnak, B. J., \& Langill, P. P. 1993, ApJ, 408, 586

Kwok, S., Hrivnak, B. J., Zhang, C. Y., \& Langill, P. P. 1996, ApJ, 472, 287

Kwok, S., Su, K. Y. L., \& Hrivnak, B. J. 1998, ApJ, 501, L117

Kwok, S., Volk, K., \& Bernath, P. 2001, ApJ, 554, L87

Kwok, S., Volk, K., \& Hrivnak, B. J. 1989, ApJ, 345, L51 1999, A\&A, 350, L35

Lame, N. J., \& Ferland, G. J. 1991, ApJ, 367, 208

Likkel, L., Forveille, T., Omont, A., \& Morris, M. 1988, A\&A, 198, L1

Likkel, L., Morris, M., Kastner, J. H., \& Forveille, T. 1994, A\&A, 282, 190

Loup, C., Forveille, T., Omont, A., \& Paul, J. F. 1993, A\&AS, 99, 291

Meixner, M., et al. 1993, ApJ, 411, 266

Millar, T. J., \& Herbst, E. 1994, A\&A, 288, 561

Mitchell, G. F., Hasegawa, T. I., \& Schella, J. 1992, ApJ, 386, 604

Olofsson, H. 1996, in IAU Symp. 178, Molecules in Astrophysics: Probes \&

Processes, ed. E. van Dishoeck (Dordrecht: Kluwer), 457
Omont, A., Loup, C., Forveille, T., te Lintel Hekkert, P., Habing, H., \& Sivagnanam, P. 1993, A\&A, 267, 515

Perinotto, M. 1991, ApJS, 76, 687

Phillips, T. G., \& Huggins, P. J. 1981, ApJ, 251, 533

Pottasch, S. R., Beintema, D., Dominguez-Rodriguez, F. J., Schaeidt, S., Valentijn, E., \& Vandenbusseche, B. 1996, A\&A, 315, L261

Rodríguez, L. F., \& García-Barreto, J. A. 1984, Rev. Mexicana Astron. Astrofis., 9,153

Rodríguez, L. F., García-Barreto, J. A., \& Gómez, Y. 1985, Rev. Mexicana Astron. Astrofis., 11, 109

Sahai, R., Wooten, A., \& Clegg, R. E. S. 1993, IAU Symp. 155, Planetary Nebulae, ed. R. Weinberger \& A. Acker (Dordrecht: Kluwer), 229

Shibata, K. M., Tamura, S., Deguchi, S., Hirano, N., Kameya, O., Kasuga, T. 1989, ApJ, 345, L55

Su, K. Y. L., Volk, K., Kwok, S., \& Hrivnak, B. J. 1998, ApJ, 508, 744

van der Veen, W. E. C. J., Huggins, P. J., \& Matthews, H. E. 1998, ApJ, 505,749

Volk, K., \& Kwok, S. 1997, ApJ, 477, 722

Volk, K., Kwok, S., \& Langill, P. P. 1992, ApJ, 391, 285

Volk, K., Kwok, S., \& Woodsworth, A. W. 1993, ApJ, 402, 292

Volk, K., Xiong, G.-Z., \& Kwok, S. 2000, ApJ, 530, 408

Young, K. 1994, Ph.D. thesis, California Inst. Tech.

1997, ApJ, 488, L157

Young, K., Cox, P., Huggins, P. J., Forveille, T., \& Bachiller, R. 1997, ApJ, 482, L101 